\title{
Pre-Service Teachers Making Sense of Fraction Division with Remainders
}

\author{
Nesrin Sahin ${ }^{1^{*}}$, Rebecca Gault ${ }^{2}$, Laura Tapp ${ }^{3}$, Juli K. Dixon ${ }^{4}$ \\ ${ }^{1}$ University of Central Arkansas, USA \\ ${ }^{2}$ University of West Georgia, USA \\ ${ }^{3}$ Alvin College, USA \\ ${ }^{4}$ University of Central Florida, USA \\ *CORRESPONDENCE: $\square$ nesrins@uca.edu
}

\begin{abstract}
This study reports an analysis of how pre-service teachers $(n=34)$ made sense of fraction division with remainders using pictorial modeling strategies, and how small-group and whole-class discussion helped them develop conceptual understanding. One and a half class sessions were video recorded, and 12 interviews were conducted. Results indicate that pre-service teachers can develop a conceptual understanding of fraction division with remainders using modeling strategies, and their understanding emerges in three levels: a) level one: ignoring the remainder or labeling it incorrectly; b) level two: interpreting the remainder in the original unit but not relating it to the new unit; and c) level three: interpreting the remainder both in the original unit and the new unit flexibly.
\end{abstract}

Keywords: pre-service teacher education, fractions, fraction division, remainder

\section{INTRODUCTION}

The Common Core State Standards for Mathematics (CCSSM) state that students should be able to “... solve word problems involving division of fractions by fractions, e.g., by using visual fraction models and equations to represent the problem" (National Governors Association Center for Best Practices \& Council of Chief State School Officers (NGA \& CCSSO), 2010, p. 42). Sharp and Adams (2002) reported that $5^{\text {th }}$ grade students who participated in their study developed solutions that include pictorial methods and symbolic procedures such as repeated subtraction, but none invented the invert and multiply procedure. The use of pictorial representations can be an important way for children to express their mathematical thinking (Woleck, 2001). Teachers' own conceptual understanding of mathematical ideas is a prerequisite to teaching students for understanding (Ball \& Bass, 2000). Therefore, it is important for pre-service teachers (PSTs) to make sense of both pictorial and symbolic representations for fraction division (Lubinski, Fox, \& Thomason, 1998). In the case of fraction division, teachers need to know how fraction division works, and why it works so that they can apply this content knowledge to facilitate students as they build conceptual understanding (Cramer, Monson, Whitney, Leavitt, \& Wyberg, 2010). This study focuses on how PSTs develop an understanding of the remainder in fraction division during class instruction that emphasizes the use of pictorial modeling strategies.

Article History: Received 13 January $2019 \bullet$ Revised 23 August $2019 \bullet$ Accepted 28 August 2019

(C) 2020 by the authors; licensee Modestum Ltd., UK. Open Access terms of the Creative Commons Attribution 4.0 International License (http://creativecommons.org/licenses/by/4.0/) apply. The license permits unrestricted use, distribution, and reproduction in any medium, on the condition that users give exact credit to the original author(s) and the source, provide a link to the Creative Commons license, and indicate if they made any changes. 


\section{BACKGROUND}

The Mathematics Advisory Panel (2008) states that "A major goal for K-8 mathematics education should be proficiency with fractions ..., for such proficiency is foundational for algebra and, at the present time, seems to be severely underdeveloped" ( $p$. xvii). Fraction concepts are "the most difficult to teach, the most mathematically complex, the most cognitively challenging" among all the topics included in the school curriculum (Lamon, 2007, p. 629). Specifically, fraction division has been identified as one of the most difficult concepts in elementary mathematics (Elashhab, 1978; Warrington, 1997). Many students learn this concept through the "invert and multiply" procedure without making sense of why the procedure works (Hanselman, 1997). Riddle and Rodzwell (2000) argue that many students lack sound understanding of fractions because instruction rushes into symbolic manipulation without providing students sufficient time to make sense of fractions. Siegler and Lortie-Forgues (2015) state that successful execution of fraction arithmetic computations by children as well as adults was no guarantee of understanding the procedure. There is evidence that teaching rules to students, especially before students have developed a conceptual understanding of rational numbers, hinders sense making (National Research Council, 2001; Wearne \& Kouba, 2000).

When teachers' knowledge was examined, studies indicated that both in-service teachers and PSTs in the United States lack a sound understanding of fraction division (Ball, 1990; Ma, 2010; Nillas, 2003; Li \& Kulm, 2008). Li and Kulm (2008) stated that their middle school PSTs have procedurally sound but conceptually weak understanding of fraction division. Lo and Luo (2012) conducted a study with Taiwanese PSTs and concluded that the task of representing fraction division with pictorial diagrams were challenging even for those highly proficient in elementary and middle school mathematics. On the other hand, Lubinski, Fox and Thomason (1998) documented how one PST, Rebecca, developed an in depth understanding by reflecting on her own reasoning and sense making processes as she developed meaning for a fraction division problem. Wheeldon (2008) claimed that PSTs can build conceptual understanding of fractions by replacing traditional rote algorithms with modeling and reasoning strategies.

Therefore, the type of instruction that PSTs receive as students is important for at least two reasons. First, teachers are inclined to use pedagogical approaches consistent with their own experiences as students (Blanton, 2002), and second, the type of instruction that PSTs receive during their mathematics methods or content for teaching courses influence their conceptual understanding of mathematics (Rayner, Pitsolantis, \& Osana, 2009).

With the implementation of the CCSSM, teachers are expected to help their students build conceptual understanding of mathematics (NGA \& CCSSO, 2010). As a learning method, discourse can lead students to actively construct meaning rather than passively consume teacher-demonstrated procedures (Wachira, Pourdavood, \& Skitzki, 2013). Hence, PSTs need to experience mathematics content courses that emphasize conceptual understanding as well as discourse as a learning method (Blanton, 2002). Nolan (2012) states that changing PSTs' views on discourse as a pedagogical technique is challenging because of their own past experiences in mathematics content courses. As students, they are likely to have been taught to value generating correct answers based on memorized, but not well understood, procedures (Blanton, 2002; Nolan, 2012).

Furthermore, successful discourse is dependent upon the teacher possessing a deep understanding of the concepts being taught and communicating to students to "value understanding concepts rather than just getting the right answers" (Wachira et al., 2013, p. 33). According to Dixon, Egendoerfer, and Clements (2009), the implementation of discourse must include an approach that encourages students to discuss incorrect answers, failed approaches, and ideas not yet fully developed. Students learn to value the process of making sense rather than merely the delivery of correct answers. As students become skilled at engaging in discourse, student ownership of mathematical ideas develops, and conceptual understanding supersedes procedural knowledge (Dixon, Egendoerfer, \& Clements, 2009). To be able to facilitate such discourse, teachers should have a deep conceptual understanding of the content they teach (Wachira et al., 2013).

While research agrees that PSTs have a weak conceptual understanding of fraction division, only a few studies address how PSTs make sense of the meaning of the remainder in fraction division. Understanding the remainder in fraction division requires further investigation of the concept as it relates to units and referent units (Dixon \& Tobias, 2013; Olanof, 2011). Olanof (2011) explained the dilemma of working with remainders in fraction division problems through an example as follows: "dividing $3 / 4$ by $1 / 2$ asks how many $1 / 2$ 's are there in $3 / 4$ ? The answer is 1 with $1 / 4$ left over, so a tempting answer would be $1 \frac{114}{4}$. However, by performing the algorithm, we can see that the correct answer to the problem is $1 \frac{1}{2}$. This is because while the remainder 
is $1 / 4$, this represents half of the $1 / 2$. There are $1 \frac{1 / 2}{2}$ halves in $3 / 4$ " (p. 73). More research is needed in order to understand how PSTs can make sense of this dilemma, so that mathematics educators can improve both content and methods courses for teaching that PSTs take in their undergraduate years.

\section{Research Question}

This study investigated how PSTs build conceptual knowledge of fraction division with remainders. The following research question guided this study:

How do pre-service teachers' understandings of the role of the remainder in fraction division problems develop during class instruction that emphasizes pictorial modeling strategies?

\section{METHODS}

\section{Participants and Setting}

The study participants were 34 undergraduate PSTs enrolled in an undergraduate mathematics content course for elementary education majors at a state university in the southeastern United States. The PSTs were instructed in a classroom environment that explored contextualized problems using pictorial models, emphasized collaboration and discourse in small groups, and required written explanation and justification for solutions followed by whole-class discourse guided by the instructor. There were seven groups of four to five students in the classroom. On the first day of instruction focused on fraction division, PSTs initially worked in groups on two fraction division problems, one with a remainder and one without a remainder. The problem without a remainder was not the focus of this study, so we only discussed the problem with a remainder in this paper. The problem with a remainder was situated in a context for which $2 / 3$ of a pan of brownies represented a serving and the task required that PSTs determine how many servings there are in 4 $5 / 6$ pans of brownies. The problem did not specify whether the servings should be whole servings, or if students should use all of the brownies. We wanted this ambiguity to exist in the problem so that we could see how PSTs would think about the remainder. PSTs were expected to use a pictorial model to solve the problem because the class instruction had emphasized the pictorial models since the beginning of the fraction unit. They worked in small groups while the instructor circulated between groups to observe solution strategies and ask probing questions when necessary to move reasoning forward. After solving the problems, members of each group collaborated to develop posters depicting their solution strategies that used pictorial models along with written explanations and justifications for their work. These posters were used later as a focal point for the whole class discussion in which the class engaged in discourse about the various solutions and reasoning strategies evident across the seven groups.

\section{Data Collection}

We presented PSTs with a contextualized fraction division problem with a remainder to solve independently before class instruction, in groups during class instruction, independently on the unit test (after class instruction) and during student interviews. At each point, we posed a different problem and asked them to explain and justify their solution strategies. About three and a half class meetings, each two hours long, were devoted to fraction division. We video-recorded the first one and one-half days of class instruction where PSTs were introduced to fraction division. Fifteen PST interviews were scheduled on a voluntary basis, with 12 interviews ultimately conducted. Three interviews were canceled due to scheduling conflicts. (See Appendix A for the interview protocol). We also video recorded the interviews. Table 1 shows the problems that were solved by the PSTs at each data collection point. 
Table 1. Problems Solved by Pre-service Teachers at Each Data Collection Point

\begin{tabular}{ll}
\hline Time of data collection & Problem \\
$\begin{array}{l}\text { Before class instruction } \\
\text { Problem solved by PSTs } \\
\text { independently) }\end{array}$ & $\begin{array}{l}\text { Justin has } 5 \text { 1/3 pounds of candy. He wants to make goodie bags, each } \\
\text { consisting of } 5 / 6 \text { of a pound of candy. Using all of the candy, how many goodie } \\
\text { bags can Justin make? }\end{array}$ \\
\hline $\begin{array}{l}\text { During class instruction } \\
\text { (Problem solved by PSTs in } \\
\text { groups) }\end{array}$ & $\begin{array}{l}\text { Sarah made } 45 / 6 \text { pans of brownies. She knows that } 2 / 3 \text { of a pan equals one } \\
\text { serving. How many servings does Sarah have? }\end{array}$ \\
$\begin{array}{l}\text { After class instruction } \\
\text { (Problem solved by PSTs } \\
\text { independently) }\end{array}$ & $\begin{array}{l}\text { Riley had } 25 / 6 \text { small pizzas leftover after the party. She wanted to pack up the } \\
\text { leftovers to give to her friends. A serving of a pizza is } 2 / 3 \text { of a small pizza. How } \\
\text { many servings can Riley make using all the leftover pizzas? }\end{array}$ \\
$\begin{array}{l}\text { During PST interviews } \\
\text { (Problem solved by PSTs } \\
\text { independently) }\end{array}$ & $\begin{array}{l}\text { Carla has } 5 \text { 1/3 candy bars. She knows } 5 / 6 \text { of a candy bar is a serving. Using all } \\
\text { of the candy bars, how many servings does Carla have? }\end{array}$ \\
\hline
\end{tabular}

\section{Data Analysis}

We calculated descriptive statistics of PSTs' solutions before and after class instruction. Information on correctness of answers, solution strategy, and labeling of answers was generated. The data collected before class instruction were used to determine the solution strategies PSTs used initially. The data collected after class instruction were used to investigate whether PSTs were able to make sense of pictorial modeling strategies, and if so, to what extent?

The data collected during class instruction and during PST interviews were used to identify common themes. We transcribed the video recordings of the class instruction (both small-group and whole-class discussions). Then we reviewed all transcripts to begin categorizing the data and identifying emerging codes. Emergent codes were used to identify themes. We also transcribed and coded the interviews and looked for data that corresponded to existing themes as well as examined the data for any new themes.

\section{RESULTS \\ Before Class Instruction}

Before class instruction on fraction division, we asked PSTs to solve a contextualized fraction division problem with a remainder and to provide an explanation and justification for their solutions. The question specifically called for the use of the leftover piece, because we wanted to see how the PSTs would interpret the remainder before instruction. Twenty-three of 34 PSTs used the invert and multiply algorithm. Other strategies used included pictures, repeated addition or subtraction, and the common denominator algorithm. Table 2 shows the frequency of each strategy used, the frequency of correct answers obtained, and the number of correct answers that were labeled with the appropriate unit. Data regarding the labeling of answers were collected because the problem was provided in context.

Table 2. Strategies Used by Pre-service Teachers Before Class Instruction

\begin{tabular}{lccc}
\hline Strategy Name & $\begin{array}{c}\text { Number of PSTs } \\
\text { used the strategy }\end{array}$ & $\begin{array}{c}\text { Number of } \\
\text { correct answers }\end{array}$ & $\begin{array}{c}\text { Number of correct } \\
\text { answers labeled }\end{array}$ \\
\hline Invert and Multiply Algorithm & 23 & 6 & 2 \\
\hline Picture & 5 & 0 & NA \\
\hline Repeated Addition or Subtraction & 2 & 0 & NA \\
\hline $\begin{array}{l}\text { Other (E.g. Common denominator algorithm, } \\
\text { Decimals, Reasoning Strategy) }\end{array}$ & 4 & 0 & NA \\
\hline
\end{tabular}

Of the PSTs who used the algorithm, 26\% obtained the correct numeric answer of $62 / 5$, and only two of those who gave correct numeric answers labeled their solution. PSTs who gave correct numeric answers did not give conceptual explanations, but rather referenced the procedure used with most saying that they used the "Keep, Change, Flip" method. Seventy-four percent of PSTs who used an algorithm did not obtain the correct answer. The errors included multiplying across without "flipping" the second fraction, incorrectly changing the mixed number to an improper fraction, cross multiplying after flipping the second fraction, 
adding after flipping the second fraction, and neglecting to properly interpret the remainder (for example, leaving the answer as 6 with 6 leftover). Five PSTs tried to use pictures, however none of them obtained the correct answer. Their explanations for their pictures consisted of statements such as "I guessed" or "I used pictures." Several other PSTs used strategies such as repeated addition or subtraction, or the common denominator algorithm, but they did not obtain the correct answer, either.

\section{How PSTs Made Sense of the Remainder in One Small Group During Class Instruction}

There were five PSTs in this group with four (Angela, Nichole, Melissa, and Laura) actively participating in the group discussion. The problem posed was 'Sarah made $45 / 6$ pans of brownies. She knows that 2/3 of a pan equals one serving. How many servings does Sarah have?'. First, students solved the problem individually using pictures. When everyone finished solving, Angela started the discussion. She explained that she drew 4 $5 / 6$, and divided it into sixths. Then she grouped the $4 / 6 \mathrm{~s}$ because she knew $2 / 3$ is equivalent to $4 / 6$. She said she could make seven full servings and $1 / 4$ of another serving, so her answer was $71 / 4$ servings. However, Nichole's answer was 7 1/6 and she did not understand how Angela got 1/4 instead of 1/6. Angela's response to Nichole's query is provided here.

Angela: Because that's 1/6 of a whole, but your answer is in serving sizes. How many servings and we know a serving is $2 / 3$.... So, I was able to make seven servings, and then I have $1 / 6$ left. I knew that, that's $1 / 6$ of a whole. I am trying to find out what that $1 / 6$ would be of my $2 / 3$. So I drew a new picture ... and cut my pan in thirds and I marked out $1 / 3$, so I was left with $2 / 3$. Now I know that I need to find the sixths. So I cut each of my thirds in half. ... And I colored my sixths. Now looking at $2 / 3$... and I see that there are four pieces.

Nichole seemed confused with this explanation and next Melissa tried to explain her solution which matched with Angela's solution. In her solution Melissa divided 4 5/6 into sixths and color-coded each serving. Melissa's work is shown in Figure 1.

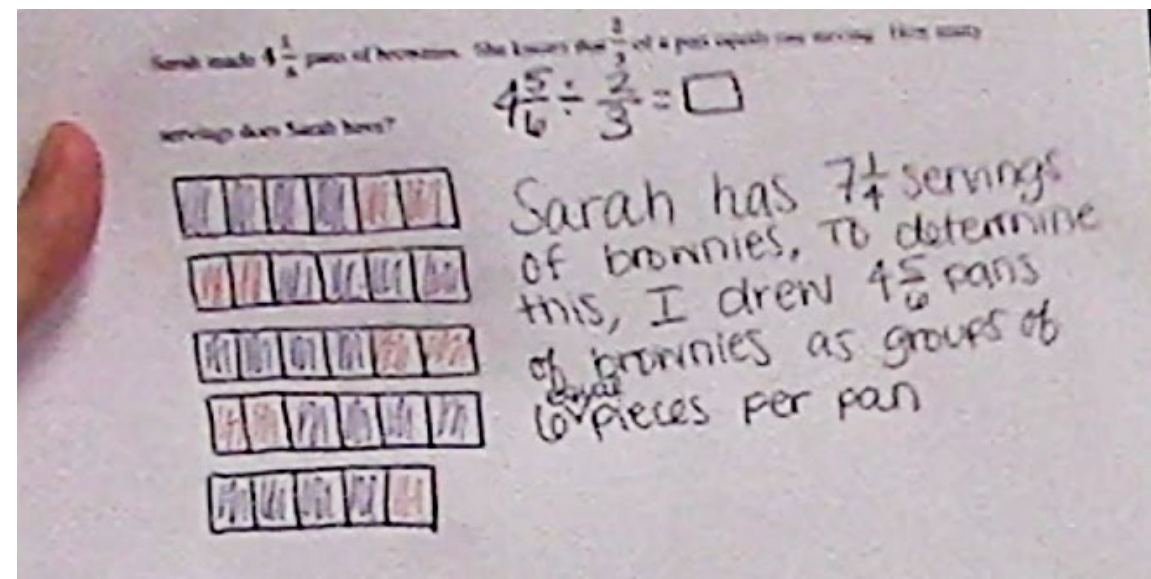

Figure 1. Melissa's written work in response to the small group problem

Melissa: You see how there are four colors in each. ... It goes four in a group, like there should be three more here [on the last one to make a serving]

Nichole was still looking at the representation of a whole pan instead of looking at the serving consisting of four one-sixths. The representation of the last pan had been divided into six equal groups, so she said:

Nichole: But that's not four in a group, that's six. See, that's why I don't understand the fourth. ...

Then Angela continued;

Angela: $\quad$ So if you get the 1/6, that's $1 / 6$ out of a whole pan, right? You are trying to figure out how many servings there are. So your whole is just $2 / 3$ of a pan.

Next, Laura joined the discussion.

Laura: It's 1/4. You have 1/4 of the 2/3. Because you need to have three more pieces if you have a full serving.... It's a fourth of your $2 / 3$. There are four pieces [in a serving] and you have one of those four pieces. 
After these explanations, it was still not clear for Nichole why the answer should be 7 1/4 servings and not 7 1/6 servings. And she said:

\section{Nichole: I understand the 1/4, but at the same time I don't.}

Then, the PSTs started to write their explanations and justifications for their solutions. Throughout this process, questioning between group members continued because many PSTs struggled to explain their reasoning in written form that had been developed during discussion. Many expressed sentiments that were in line with one student, who said, "I feel like I could explain it out loud. Could we take our test orally?". When the PSTs finished writing explanations for their solutions, each group agreed upon one solution as their group's solution and created a poster showing their pictorial solution strategy along with a written explanation of the strategy.

\section{How PSTs Made Sense of the Remainder During Whole Class Discussion}

The second day of instruction started with posting the posters on the white board and a whole class discussion focused on the PSTs' solutions. Four groups claimed that there were $71 / 4$ servings, one group claimed there were 7 servings with $1 / 6$ of a pan left over, another group claimed 7 1/6 servings, and the remaining two groups claimed 7 whole servings. To start the class discussion, the instructor called one or two students to explain their group's solution for each different answer, starting with the correct answer. Taylor volunteered to explain the solution for her group.

Taylor: $\quad$ So, there are 4 5/6 pans of brownies. And we need to find out how many servings we can make out of that. You know a serving is $2 / 3$. [Taylor goes on to describe how she drew $45 / 6$ and how she determined how many serving are in $45 / 6$ by thinking of a serving as $4 / 6]$. ... So, next $I$ grouped my pieces into 4/6. And I was able to make seven whole groups and then I have 1/6 left of a whole pan of brownies. However, I know that the answer is not $71 / 6$ because my whole is not whole pan of brownies. My whole is $2 / 3$ of a pan of brownies or a serving... So that's $1 / 6$ of a whole [pan] but it's $1 / 4$ of $2 / 3$. Because if you are only looking at the $2 / 3$, you see that you only have four pieces. So, your answer is $71 / 4$ servings of brownies.

After Taylor's explanation, one more student from a different group who obtained the same answer explained her solution, which was similar to Taylor's explanation. Then, the instructor elaborated on the solutions by asking questions of the students focused on why there was 1/6 of a whole pan, but 1/4 of a serving. After making sure that the class understood the 1/4 serving in the solution, the instructor called another student, Katie, from group six who got 7 1/6 servings as the answer.

Katie: $\quad$ We counted wrong because we counted them as pans of brownies at the end, the left over. We did it the same way in the beginning but we counted the pan of brownies instead of servings.

Then, the instructor asked the class what would 7 and 1/6 represent in the answer 7 1/6. After some discussion, the class agreed that 7 represented the number of servings but $1 / 6$ represented how much of a pan was left over. So, the answer could be that she could make 7 servings with $1 / 6$ of a pan of brownies leftover. One student raised this question: "If I leave my answer as 7 servings with 1/6 of a pan of brownies left over, would that be counted as right?" Several students responded that it would not be correct because the question asks for the answer to be reported in servings. During this discussion, the instructor did not specify any answer as correct or incorrect because she wanted her students to hear the reasoning for each different answer. So, she called on groups seven and eight who each found 7 servings as their answers. From one of these groups, one student explained that they only considered finding whole servings but not the partial servings, because in real life they would not talk about partial servings and this justified ignoring the remainder. Several PSTs commented that the answer 7 referred to "whole servings", rather than "servings", so it would not be right. Next, the instructor asked students to discuss in their small groups which of these answers could be considered reasonable and under what circumstances. After the PSTs discussed in their groups, the instructor brought the class back to a whole-class discussion to share their thoughts.

Adam: I think that any other people that got 7 and $1 / 6$ left over is wrong. Because we're not talking about the whole pan, ... we're talking about the servings. The question's not asking for what's remaining and asking what's a serving. So when they said 7 servings, it's also correct because those are seven complete servings...

Anna: $\quad$ I will disagree... Because; I think as long as you label it correctly you will have the right answer. 
Stephanie: I think it's important to interpret the directions and look what you are being asked for... I would give partial credit to the people who got seven, because they did get it mostly right.

Sarah: I don't think it was too detailed, like they're not specific [referring to the directions in the problem].

Several PSTs pointed out that the directions refer to creating servings.

Mary: It says how many servings that you have; it does not ask how much left over... We did whole because they ask how many servings. Not like, it specifically didn't say in the question -and how many left over, or partial servings.

Annette: We put seven, and I think 71/4 is correct, because it did not ask for whole servings. If it had asked whole servings, seven would have been right. But since it said servings, you do have 7 and then $1 / 4$ of a serving...

Melissa: $\quad$ This [question] is very broad that's why we have three different answers ...

Kamila: If you use the correct unit for the 1/6, then would that still be acceptable?

Laura: $\quad$ You have to say how much of what is left over. So either, how many full servings and how much of a pan is left or how many full servings and how much of a serving is left. You have to say oneway or the other.

At the end of the class discussion, with the guidance of the instructor, the class decided that $71 / 4$ servings was the correct answer; however other answers (such as 7 full servings, and 7 servings with 1/6 of a pan left over) would also be mathematically correct due to the ambiguity in the problem statement because it did not specify that the answer should include partial servings or that they should use all of the brownies.

\section{Emerging Theme from Classroom Observation}

During classroom observations one main theme emerged: Some PSTs struggled with understanding, and therefore labeling the leftover in the fraction division problem that had a remainder. We found that PSTs' understanding of the role of the remainder in fraction division emerged in three levels. Pre-service teachers who were in level one could represent the problem pictorially but they would either ignore the remainder or they would label the remainder incorrectly. PSTs in level two could represent the problem pictorially, but only interpret the remainder in the original units (attended to and labeled what was left over from a pan of brownies). Pre-service teachers who were in level three could represent the problem pictorially, and could interpret the remainder in the new unit and in the original unit flexibly and correctly. Figures 2-4 illustrate a typical PST's solution and/or explanation according to the three levels of understanding.
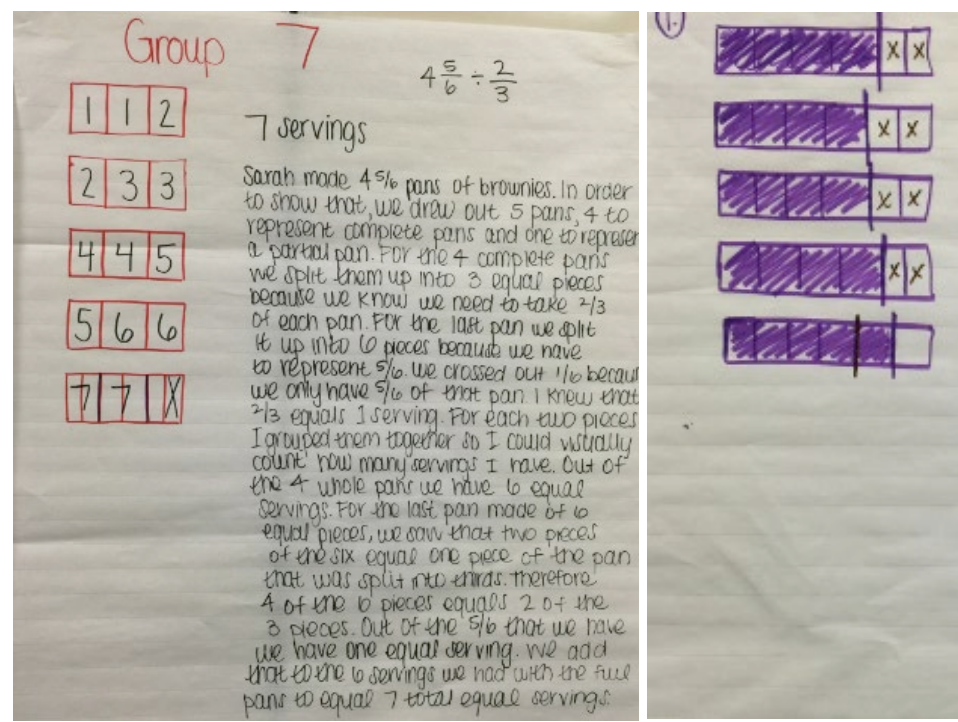

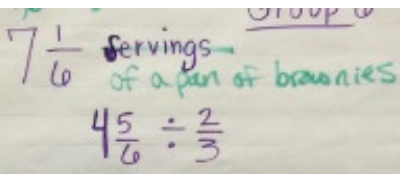

- First I drew 4 pans of broconits and one more pan split into sixths with $5 / 6$ shoded. Next I know I need equal preces So I cut each whole pan into 6 equal preces. I know $\frac{2}{3}$ of a pan equals one senving. I know that if I group the sixths into three equace parts I get two peeces in each so that $1 / 3$ is equal to $2 / 6$. Knowing this I gmoped each $4 / 6$ together to get $2 / 3$, which is equal to one serving of a browhie. Then I counted how many groupr of 4/6 I had and I got 7 grous with $1 / 6$ leftover So Sarah had $7 \frac{1}{6}$ senings of brownies

Figure 2. Example solution for level one understanding. In this level, students are able to represent the problem pictorially but ignore the remainder or interpret it incorrectly 

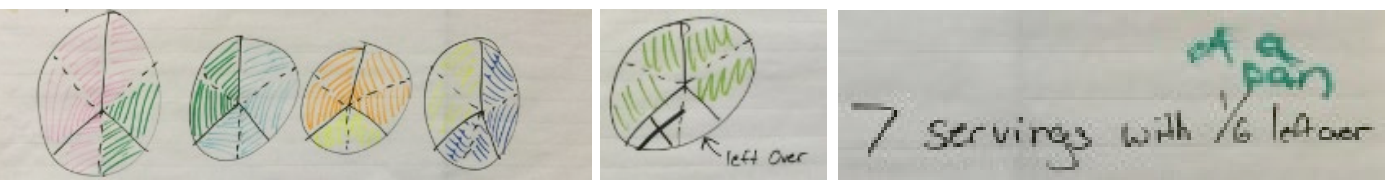

Figure 3. Example solution for level two understanding. In this level, students are able to represent the problem pictorially but represent the remainder in the original units only
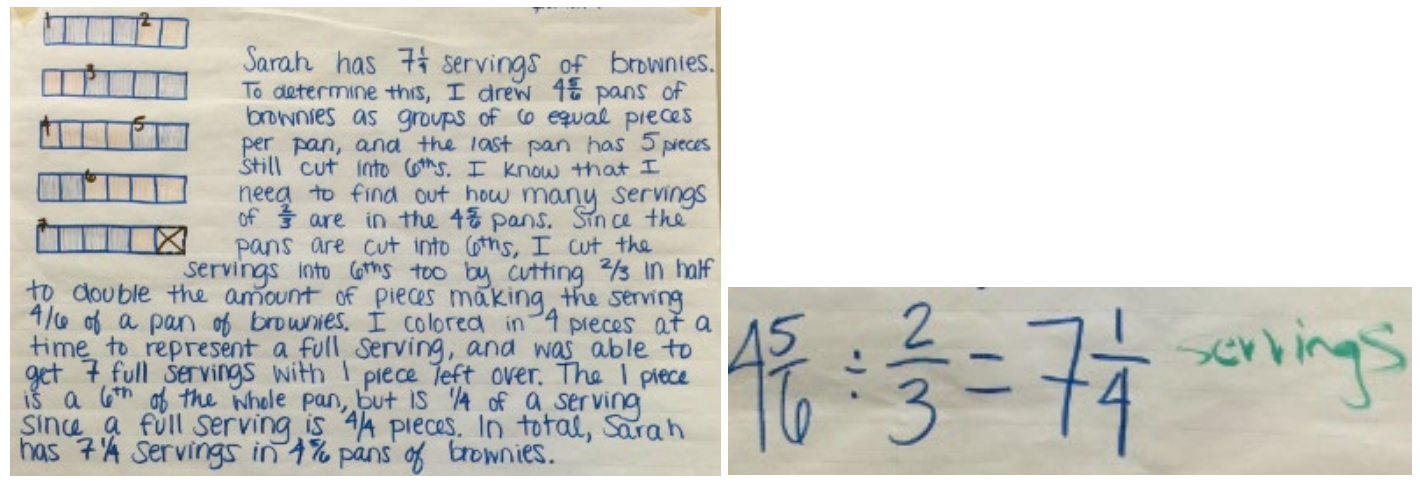

Figure 4. Example solution for level three understanding. In this level, students are able to represent the problem pictorially and represent the remainder both in the original and new units

\section{After Class Instruction}

PSTs were asked to solve a contextualized fraction division problem with a remainder on their unit test, and they were asked to explain and justify their solution strategy. The question specifically called for the use of the leftover piece, because we wanted to see how PSTs would interpret the remainder after the class instruction. Since class instruction focused on the pictorial modeling strategies, all PSTs used a pictorial model to solve the problem. About $60 \%$ of PSTs obtained a correct answer and provided conceptually-based explanations and justifications for their solutions. All PSTs who obtained a correct answer also labeled their solutions correctly. Table 3 displays the strategy used, number of correct answer and number of correct answers that were labeled.

Table 3. Strategies Used by Pre-service Teachers After Class Instruction

\begin{tabular}{lccc} 
Strategy Name & $\begin{array}{c}\text { Number of PSTs used } \\
\text { the strategy }\end{array}$ & $\begin{array}{c}\text { Number of correct } \\
\text { answers }\end{array}$ & $\begin{array}{c}\text { Number of Correct Answers } \\
\text { That Were Labeled }\end{array}$ \\
\hline Pictorial Modeling & 34 & 20 & 20 \\
\hline
\end{tabular}

We further categorized PSTs' answers from data collected both before and after the class instruction into three levels that were emerged from the class observation. Table 4 shows the number of PSTs at each level based on their answers.

Table 4. Student Responses to Fraction Division Problem Before and After Instruction Organized by Levels

\begin{tabular}{clcc}
\hline Levels & Student's Answer & $\begin{array}{c}\text { Number of PSTs } \\
\text { (Before Instruction) }\end{array}$ & $\begin{array}{c}\text { Number of PSTs } \\
\text { (After Instruction) }\end{array}$ \\
\hline One & Ignored the remainder or labeled it incorrectly & 15 & 4 \\
\hline Two & $\begin{array}{l}\text { Labeled the remainder in the original unit } \\
\text { (Interpreted the leftover in the original unit) }\end{array}$ & 2 & 6 \\
\hline Three & $\begin{array}{l}\text { Labeled the remainder in the new unit } \\
\text { (Interpreted the leftover in the new unit) }\end{array}$ & 6 & 20 \\
\hline
\end{tabular}

Note: 11 PSTs' solutions from the data collected before instruction and four PSTs' solutions from the data collected after instruction were not categorized because their answers did not make sense in the context of the given problem 


\section{Interview Observation}

Following the data collected after class instruction, we conducted 12 PST interviews. During the interviews, PSTs solved a fraction division problem with a remainder (see Table 1). The question specifically called for the use of the leftover piece, because we wanted to see how PSTs would explain their thinking when interpreting the remainder following the instruction. The interviews provided confirmation of levels 1 through 3 of understanding that describe the PSTs' grasp of the role of the remainder in fraction division.

Based on their responses, seven out of 12 PSTs were at level three, three were at level two, and two were at level one in terms of their understanding. In each of the following cases, the PSTs began by drawing a picture. What follows are excerpts from the interviews that illustrate the thinking related to each solution.

\section{The case of level one understanding}

Elizabeth: $\quad$... So, one, two, three, four, five, and six. Because $5 / 6$ is a serving, I basically counted out $5 / 6$. It's clear that using all the candy bar, she can only have 6 full servings.

Interviewer: So your answer is 6 servings?

Elizabeth: Yes, my answer is 6 servings.

Interviewer: The question says, "using all of the candy bars." Did you use all of the candy bars?

Elizabeth: $\quad$ No

Interviewer: So what do you think about it?

Elizabeth: Well, I just figured, because I was trying to use the full servings, like I could not make another serving based on $2 / 6$. So, $2 / 6$ of the whole is $1 / 3$. It's full 6 servings and then there is $1 / 3$ left over. I guess in all, she could do $61 / 3$ servings.

\section{The case of level two understanding}

Britney: $\quad$... Now I am going to count the full servings, so I have six full servings and with my two left over. I am going to say that's $2 / 6$ of the candy bar, but it's ... I really don't know how to explain it from there. So we have 6 full servings and $2 / 6$ like of the candy bar left but I know that that's not $2 / 6$ of the serving. Can I just say of the candy bar?

Interviewer: What do you think?

Britney: $\quad$... I think I'll just go ahead and say six full servings and $2 / 6$ of a candy bar left over.

\section{The case of level three understanding}

Alex: $\quad$... Ok, so I should have 6 whole servings with $2 / 6$ of a whole candy bar left, but I want to know how much of a serving that is. So, if a serving is five pieces and I have two left, then I know that it's actually $2 / 5$ of a serving. So I get $62 / 5$ servings.

\section{DISCUSSION}

Existing research revealed that PSTs have a weak conceptual understanding of fraction division (Ball, 1990; Li \& Kulm, 2008; Ma, 2010; Nillas, 2003), however only a few studies examined how they interpret the remainder in fraction division. This study aimed to fill the gap in the literature by focusing on PSTs' understanding of the role of the remainder in fraction division.

When we examined the work of PSTs before class instruction, the result was confirmation of previous studies which concluded PSTs' knowledge was mostly procedural as demonstrated by the preferred use of the invert and multiply algorithm by the majority of the class to solve the problem. However, their procedural understanding was not sound as only $26 \%$ of those who used an algorithm executed it correctly. We also confirmed that the PSTs lacked a conceptual understanding of the algorithm based on statements included in their explanations such as "I used the keep, change, flip method". The PSTs who did not use an algorithm $(32 \%)$ to solve the problem did not perform any better, because none of them were able to solve the problem correctly and provide a conceptual explanation. During the interviews, we asked about PSTs' prior classroom learning experiences concerning fraction division, and most said they learned the invert and multiply algorithm but never understood why the algorithm worked or never thought about why it worked. This was 
also reflected in the responses where many students did not include a label for the unit as part of their answers to a fraction division with a remainder problem provided in context.

In this study, we focused on pictorial modeling strategies, because we wanted to see how PSTs developed an understanding of the role of the remainder in a fraction division problem with a remainder. For example, when we solve $2 / 3 \div 5 / 6$ using repeated addition/subtraction, we obtain 3 with $1 / 6$ left over. When we employ the invert and multiply algorithm, we see that the answer is $31 / 5$. The pictorial modeling strategy provides a visual representation that has the potential to explicate the connection between the $1 / 6$ and the $1 / 5$ when interpreting the remainder.

We examined how PSTs developed a conceptual understanding of fraction division and interpreted the remainder using modeling strategies. Based on the solutions the PSTs provided to the given problem, we determined that the PSTs' understanding of the role of the remainder in fraction division emerged in three levels: (1) ignoring the remainder or labeling it incorrectly, (2) interpreting the remainder in the original unit, and (3) interpreting the remainder in the new unit and the original unit flexibly. When examining the transcripts from the whole class instruction, we were not sure whether the PSTs who preferred to ignore the remainder did so because they could not make sense of it, or because they thought the problem was not asking for the remainder since there was ambiguity in the problem. However, the data collected after class instruction revealed that six out of 34 PSTs still ignored the remainder even though the problem specifically called for the leftover piece to be addressed in the solution. Additionally, during the interviews one of the PSTs who ignored the remainder was not able to interpret it correctly when specifically asked questions about the remainder, which shows that interpreting the remainder continued to be a challenge for some PSTs.

In our study, a majority of our PSTs (60\%) gained a conceptual understanding of fraction division with remainders. This result reveals that PSTs can make sense of the remainder in fraction division when they participate in a learning environment focused on conceptual understanding using pictorial modeling strategies, which is a required knowledge for them to teach fractions with understanding.

\section{LIMITATIONS}

This study was a case study where the class was considered as a case. Results are not generalizable beyond the single case being studied (Creswell, 2007). We used a purposive sampling, which is particularly vulnerable to sampling bias (Creswell, 2007). In addition, study participants volunteered for interviews. It is possible that participants who did not volunteer to be interviewed might have provided different or conflicting data than participants who did volunteer to be interviewed.

\section{IMPLICATIONS}

It seems evident from the data and the supporting research that PSTs should be given ample opportunity to solve fraction division problems in context with visual and symbolic representations to uncover potential misconceptions. The contextualized fraction division problems that PSTs solve must include those that contain remainders to allow PSTs to develop conceptual understanding of what the remainder is, how to label it, and how to think flexibly about it. PSTs also need to be given the opportunity to generate solutions to problems with small groups, as well as the opportunity to participate in whole-class discussions so they can make sense of other students' solutions.

Future research in this area should examine the knowledge of in-service teachers to determine if they have similar gaps in understanding as the PSTs studied here. There should also be a follow-up on PSTs who participate in an instructional environment similar to that described here to determine if they continue to solve fraction problems conceptually and can better make sense of the algorithms used to solve similar problems. Additionally, research should look at the future work of PSTs as classroom teachers to determine if knowledge about remainders in fraction division developed during college methods and content for teaching courses impacts their teaching approaches. Future research should also focus on the thinking of the students who perceive the remainder as just being a left-over piece that should be discarded and the thinking of those who could not see the remainder flexibly both in the original unit and as part of the new unit.

\section{Disclosure statement}

No potential conflict of interest was reported by the authors. 


\section{Notes on contributors}

Nesrin Sahin - University of Central Arkansas, USA.

Rebecca Gault - University of West Georgia, USA.

Laura - Tapp - Alvin College, USA.

Juli K. Dixon - University of Central Florida, USA.

\section{REFERENCES}

Ball, D. L. (1990). The mathematical understandings that preservice teachers bring to teacher education. The Elementary School Journal, 90(4), 449-466. https://doi.org/10.1086/461626

Ball, D. L., \& Bass, H. (2000). Interweaving content and pedagogy in Teaching and Learning to Teach: Knowing and Using Mathematics. In J. Boaler (Ed.), Multiple Perspectives on Mathematics Teaching and Learning, (pp. 83-104). Westport, London: Ablex

Blanton, M. L. (2002). Using an undergraduate geometry course to challenge pre-service teachers' notions of discourse. Journal of Mathematics Teacher Education, 5(2), 117-152. https://doi.org/10.1023/A:1015813514009

Cramer, K., Monson, D., Whitney, S., Leavitt, S., \& Wyberg, T. (2010). Dividing fractions and problem solving. Mathematics Teaching in the Middle School, 15(6), 338-46.

Creswell, J. W. (2007). Qualitative inquiry and research design: Choosing among five traditions (2 $2^{\text {nd }}$ ed.) Thousand Oaks, CA: Sage.

Dixon, J. K., \& Tobias, J. M. (2013). The Whole Story: Understanding Fraction Computation. Mathematics Teaching in the Middle School, 19(3), 156-163.

Dixon, J. K., Egendoerfer, L. S., \& Clements, T. (2009). Do they really need to raise their hands? Challenging a traditional social norm in a second grade classroom. Teaching and Teacher Education, 25, 1067-1076.

Elashhab, G. A. (1978). Division of Fractions-Discovery and Verification. School Science and Mathematics, 78(2), 159-162. https://doi.org/10.1111/j.1949-8594.1978.tb09334.x

Hanselman, C. (1997). Stop Using Foul Language in the Mathematics Classroom. Mathematics Teaching in the Middle School, 3(2), 154-160.

Lamon, S. (2007). Rational numbers and proportional reasoning. In F. Lester (Ed.), Second handbook of research on mathematics teaching and learning (pp. 629-666). Charlotte, NC: Information Age Publishing.

Li, Y., \& Kulm, G. (2008). Knowledge and confidence of pre-service mathematics teachers: the case of fraction division. ZDM-The International Journal on Mathematics Education, 40, 833-843. https://doi.org/10.1007/s11858-008-0148-2

Lo, J. J., \& Luo, F. (2012). Prospective elementary teachers' knowledge of fraction division. Journal of Mathematics Teacher Education, 15(6), 481-500. https://oi.org/10.1007/s10857-012-9221-4

Lubinski, C. A., Fox, T., \& Thomason, R. (1998). Learning to Make Sense of Division of Fractions: One K-8 Preservice Teacher's Perspective. School Science and Mathematics, 98(5), 247-259. https://doi.org/10.1111/j.1949-8594.1998.tb17298.x

Ma, L. (2010). Knowing and teaching elementary mathematics: Teachers' understanding of fundamental mathematics in China and the United States. Routledge.

National Governors Association (NGA) Center for Best Practices \& Council of Chief State School Officers (CCSSO). (2010). Common core state standards for mathematics. Washington, DC: Author.

National Mathematics Advisory Panel (NMAP). (2008). Foundations for success: The final report of the National Mathematics Advisory Panel. Washington, DC: U.S. Department of Education. Retrieved on November 11, 2008, from http://www.ed.gov/about/bdscomm/list/mathpanel/report/final-report.pdf

National Research Council (NRC). (2001). Adding It Up: Helping Children Learn Mathematics. J. Kilpatrick, J. Swafford, \& B. Findell (Eds.). Mathematics Learning Study Committee, Center for Education, Division of Behavioral and Social Sciences and Education. Washington, DC: National Academy Press.

Nillas, L. (2003). Division of Fractions: Preservice Teachers' Understanding and Use of Problem Solving Strategies. The Mathematics Educator, 7(2), 96-113. 
Nolan, K. (2012). Dispositions in the field: Viewing mathematics teacher education through the lens of Bourdieu's social field theory. Educational Studies in Mathematics. https://doi.org/10.1007/s10649-0119355-9

Olanoff, D. A. (2011). Mathematical Knowledge for Teaching Teachers: The Case of Multiplication and Division of Fractions (Unpublished doctoral dissertation thesis). Syracuse University, USA

Rayner, V., Pitsolantis, N., \& Osana, H. (2009). Mathematics anxiety in preservice teachers; Its relationship to their conceptual and procedural knowledge of fractions. Mathematics Education Research Journal, 21(3), 60-85. https://doi.org/10.1007/BF03217553

Riddle, M., \& Rodzwell, B. (2000). Fractions: What happens between kindergarten and the army?. Teaching children mathematics, 7(4), 202.

Sharp, J., \& Adams, B. (2002). Children's constructions of knowledge for fraction division after solving realistic problems. The Journal of Educational Research, 95(6), 333-347. https://doi.org/10.1080/00220670209596608

Siegler, R. S., \& Lortie-Forgues, H. (2015). Conceptual knowledge of fraction arithmetic. Journal of Educational Psychology, 107(3), 909. https://doi.org/10.1037/edu0000025

Wachira, P., Pourdavood, R. G., \& Skitzki, R. (2013). Mathematics teacher's role in promoting classroom discourse. International Journal of Mathematics Teaching and Learning. Retrieved from www.cimt.plymouth.ac.uk/journal/wachira.pdf

Warrington, M. A. (1997). How Children Think about Division with Fractions. Mathematics Teaching in the Middle School, 2(6), 390-94.

Wearne, D., \& Kouba, V. L. (2000). Rational Numbers. In E. A. Silver and P. A. Kenny (Eds.), Results from the Seventh Mathematics Assessment of the National Assessment of Education Progress. Reston, VA: National Council of Teachers of Mathematics.

Wheeldon, D. A. (2008). Developing mathematical practices in a social context. [electronic resource] : an instructional sequence to support prospective elementary teachers' learning of fractions. Orlando, Fla.: University of Central Florida, 2008.

Woleck, K. R. (2001). Listen to their pictures: An investigation of children's mathematical drawings. In A. A. Cuoco \& F. R. Curcio (Eds.), The roles of representation in school mathematics (pp.215-227). Reston, VA: NCTM. 


\section{APPENDIX A}

\section{Interview Protocol}

$\mathrm{Hi}$, my name is

I'm working on the research study that you volunteered to participate in. Thank you for volunteering to participate in this study and specifically this interview.

Before we begin, I'd like to make sure that I have your name correct. Will you please tell me your name? [Match name to subject number.]

What year is this for you in college?

1. I'd like to give you this problem to solve. Can you talk through what you are thinking as you work this problem? I'd like to hear your thinking about solving the problem as you solve it. [Participant will be given the original fraction division problem to solve.]

2. Can you explain your solution (answer)?

a. What does your remainder mean?

b. How did you label your solution?

3. What was your thought process when working the problem?

[Questions about experiences in class regarding small group work and whole class discussions.]

4. How did your thinking about fraction division problems change with small group work and whole class discussion when compared to the first problem like this that you worked independently?

a. How did your thinking about the meaning of a remainder in a fraction division problem change due to small group work and whole class discussion?

5. How did you make sense of other students' thinking in the class?

6. How did the thinking of other students in your small group or the class change the way you think about solving the problem?

7. Were you able to help a member of your small group or the class understand how to solve the problem?

a. If so, can you describe how you helped that student?

8. How did your belief in your ability to solve fraction division problems with remainders change?

9. How did your belief in your ability to explain how to solve a fraction division problem with a remainder change? 